\title{
La arquitectura deportiva y el patrimonio del movimiento moderno en Latinoamérica. El caso del Estadio Nacional, Lima- Perú *
}

\author{
Sports architecture and the heritage of the modern movement in \\ Latin America. The case of the National Stadium, Lima - Peru
}

Alejandra Acevedo**

Universidad de Lima

Recibido: 4 de octubre de 2019

Aceptado: 18 de noviembre de 2019

\section{RESUMEN}

En la historia de la arquitectura del siglo XX, en la etapa identificada como movimiento moderno, se encuentran interesantes ejemplos de infraestructura deportiva que formaban parte, a la par que otros edificios, de un gran deseo por modernizar la sociedad, en este caso a través de espectáculos masivos y populares. En su momento, fueron obras de arquitectura e ingeniería muy audaces, por los retos espaciales y estructurales que tuvieron que resolver. Se repasan tres ejemplos emblemáticos en Latinoamérica y el caso particular del Estadio Nacional en Lima, desde la visión de su valor patrimonial.

Palabras clave: Estadios, Movimiento Moderno, Lima, Latinoamérica, arquitectura deportiva, patrimonio.

\begin{abstract}
In the history of 2oth century architecture, at the stage identified as the modern movement, interesting examples of sports infrastructure are found and they are part, along with other buildings, of a great desire to modernize society, in this case through massive and popular shows. At the time, they were very bold works of architecture and engineering, due to the spatial and structural challenges they had to solve. Three emblematic examples in Latin America and the particular case of the National Stadium in Lima, from the perspective of its heritage value, are reviewed.
\end{abstract}

Keywords: Stadiums, Modern Movement, Lima, Latin America, sports architecture, heritage.

\footnotetext{
* Antecedentes del documento. Este artículo forma parte del interés de la autora por las obras arquitectónicas del siglo XX, dentro de la labor que viene realizando en defensa del patrimonio del movimiento moderno durante los últimos años.

** Alejandra Acevedo de los Ríos. Arquitecta (Universidad Ricardo Palma) Candidata a Maestra en Ciencias con mención en vivienda por la Universidad Nacional de Ingeniería.
} 


\section{Introducción}

Los proyectos modernizadores, entre fines del siglo XIX y principios del XX, otorgaron un papel importante al deporte como medio de superación, algo que podía mejorar la vida de las personas. En las sociedades latinoamericanas, el deporte encarnó ideales ligados a la salud y el bienestar. En el caso del fútbol hablamos de un deporte que se extendió con mucha rapidez en el continente, con cada vez más aficionados. Al interior de cada país latinoamericano, el fútbol podía representar un sentimiento de integración de diversas capas sociales; hacia el exterior, servía como elemento de cohesión e identidad frente a otras naciones. Nada de esto fue ajeno al Perú y al desarrollo en particular del fútbol en Lima.

\section{El fútbol en Lima. \\ Cuatro estadios en un solo lugar}

Tras la demolición de las murallas de Lima, nuevas zonas de especulación y crecimiento urbano se hicieron posibles. Se establecieron zonas industriales y residenciales, estas últimas para sectores populares o acomodados. La urbanización Santa Beatriz fue una de esas áreas de expansión de la ciudad. Si el barrio de La Victoria albergó obreros, Santa Beatriz estaría destinada a sectores acomodados que abandonaban el centro histórico, un proceso que se acrecentó con la construcción de la avenida Leguía en la década de 1920.

En esa zona de extensas áreas verdes, al sur de la antigua ciudad amurallada, se ubicaron actividades recreativas y deportivas que enfatizaban las nuevas costumbres de sectores sociales que se reconocían como modernos. Estas actividades al aire libre estaban alentadas por corrientes higienistas, como beneficiosas para la salud y la moral. La práctica de deportes nuevos como el fútbol fue introducida por inmigrantes ingleses. Es decir, en un inicio fue practicada por extranjeros y miembros de la élite limeña, con una difusión restringida que fue creciendo desde las escuelas. Paulatinamente, a través de agrupaciones de futbolistas, primero estudiantes, luego provenientes de un mismo barrio o espacio laboral, nacieron los clubes deportivos: un proceso que con cier- ta rapidez dio lugar a la popularización del fútbol en Lima durante las primeras décadas del siglo XX. (Álvarez, 2016)

En el terreno de la urbanización Santa Beatriz que actualmente ocupa el Estadio Nacional del Perú han tenido lugar cuatro recintos deportivos para la práctica del fútbol. Es decir, en la misma ubicación, se ha desarrollado por más de 120 años el fútbol en nuestro país. Desde la cancha original y su modesto equipamiento, el recinto se transformó radicalmente hasta tres veces en las siguientes décadas, sin cambiar de lugar.

Un antiguo estadio existió de 1897 a 1923, cuando el fútbol adquirió proyección nacional y se hicieron cambios importantes en su estructura. Luego se construyó un nuevo estadio en 1951 que, a su vez, fue remodelado en el 2011.

La historia empieza cuando el club Unión Cricket solicitó un lugar apto para la práctica de fútbol, adjudicándoles el Consejo Municipal de Lima un terreno ubicado en las cercanías del Parque de la Exposición, en Santa Beatriz, nombre de la hacienda que anteriormente ocupaba el lugar. Su rival más importante, el club Lima Cricket, ya tenía un campo deportivo en Santa Sofía desde 1888. (Álvarez, 2019) El terreno de Santa Sofía estuvo ubicado en un lugar que hoy ocupa el ex Hospital Obrero, en la avenida Grau.

La inauguración del recinto deportivo en Santa Beatriz se dio en 1897, contando en un principio con pocas tribunas, implementado modestamente. Lo importante es que este terreno se convirtió en el principal escenario para jugar fútbol, aunque se hubieran desarrollado partidos con anterioridad en otras canchas de Lima y Callao. El estadio del Unión Cricket posibilitó una serie de actividades y deportes que tenían que ver con la modernización de la sociedad y el crecimiento de Lima hacia el sur.

Tras la desaparición del Unión Cricket, hacia 1912, el terreno que ocupaba regresó a ser propiedad del municipio, pasando a manos de la Federación de Estudiantes del Perú. La década de 1910 coincidió con el aumento de los deportistas dedicados al fútbol y comenzó a jugarse, en ese lugar, la liga pe- 
ruana. Cada vez más aficionados mostraban interés en el fútbol, haciéndose necesaria ciertas medidas de seguridad y comodidad.

En la década de 1920, Lima experimentó un proceso de importantes cambios durante el período gubernamental de Augusto B. Leguía, denominado el Oncenio. Con motivo de la celebración del Centenario de la Independencia del Perú, hubo regalos de las principales colonias extranjeras que residían en el país. La colonia británica obsequió la construcción y ampliación del estadio en Santa Beatriz. A ese nuevo recinto se le bautizó como Estadio Nacional, inaugurado en julio de 1923. Fue llamado así porque se constituyó en el principal escenario deportivo para la práctica del fútbol en el Perú.

El planteamiento inicial contemplaba un gran complejo deportivo y su construcción demoró varios años. El Estadio $\mathrm{Na}$ cional contaba con una tribuna preferencial de madera y algunos palcos laterales a nivel del piso. Contaba además con una cancha auxiliar sin tribunas. A pesar de su simplicidad era, sin dudas, mejor que el anterior.

El Estadio Nacional tuvo reformas y ampliaciones posteriores, que incluyeron la construcción de otras tribunas, siempre de madera. Ya para ese entonces era el principal campo de juego de los equipos más importantes del país, en una época en que el fútbol se consolidó como el deporte más popular del Perú.

\section{Fútbol y concreto armado}

En 1948 se decidió la ampliación del Estadio Nacional, durante el gobierno del presidente Manuel A. Odría. En 1951 fue cerrado y derruido para dar paso a la construcción de un nuevo estadio. Sus tribunas de madera fueron destinadas a otros escenarios deportivos.

El diseño del proyecto fue de Alberto Jimeno, autor de varias unidades escolares construidas también en el gobierno de Odría. Alberto Jimeno, nacido en Lima, estudió en la Escuela de Ingenieros y tuvo una relación temprana con el diseño y la construcción a través de la empresa familiar dirigida por su padre, la Compañía Construc- tora Jimeno Hermanos. Como proyectista desarrolló obras de gran envergadura en el ámbito educativo y deportivo. (Acevedo, Llona, 2016, p. 433)

El Estadio Nacional podría inscribirse en ese grupo de edificios de carácter moderno que no abandonaron criterios de composición académicos, entre ellos, la monumentalidad y la simetría. El edificio se concibió como un volumen curvo con predominancia de la masa y ventanas horizontales corridas a lo largo del edificio con una carpintería en forma de grilla ortogonal. Las líneas de ventanas corridas refuerzan la horizontalidad del edificio y acentúan los pisos con un ritmo espacial. En el basamento se aprecia claramente la estructura compuesta por un "entramado transversal cada 5 metros con 7 filas de columnas y 6 niveles de pisos" (Anónimo, 1952, p. 23). La Torre de los Homenajes con 47 metros de alto marca uno de los ingresos principales y se transformó en un hito de la ciudad. El estadio recuerda, en cierto sentido, algunas obras de la década de 1930, de rasgos clasicistas, como el Ministerio de Salud, el Instituto de enfermedades neoplásicas o el Hospital Obrero.

En el gobierno de Odría se emprendieron obras públicas con las características antes descritas, un tanto alejadas de los conceptos modernos: el Ministerio de Hacienda y el Ministerio de Trabajo, ambos con rasgos monumentales. (Martuccelli, 2017, p. 190) Edificaciones que en la década de 1950 combinan elementos modernos con académicos, de las que podemos encontrar ejemplos tanto públicos como privados. (Cuadra, 2010, p. 92, 93) El Estadio Nacional guarda alguna relación con dichas obras, modernas academicistas. Completa, con el Ministerio de Educación y el Hospital del Empleado, la lista de grandes obras monumentales del gobierno odriísta.

El Estadio Nacional se proyectó con una capacidad de aproximadamente 60000 espectadores, un área construida de 49,820 $\mathrm{m} 2$, en un terreno de 45,000 m2. El gestor del proyecto fue Miguel Dasso, Presidente de la Sociedad de Beneficencia Pública de Lima. Los ingenieros fueron Juan Caycho y Hugo Pigatti. Edificado íntegramente de concreto armado, la construcción estuvo 


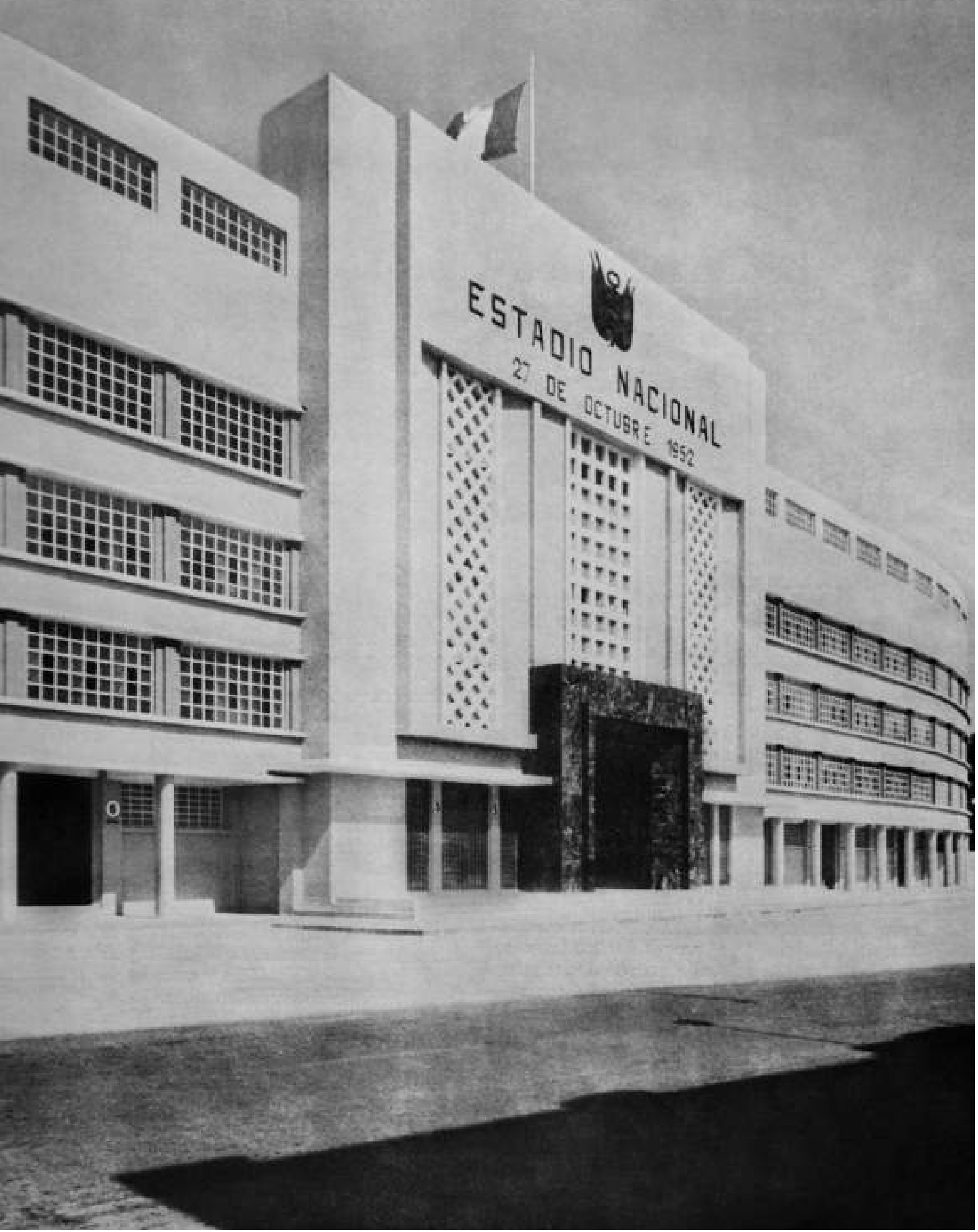

Estadio Nacional. Lima. 1952. Alberto Jimeno. Ingreso principal tribuna de occidente.

Fuente: Revista El Arquitecto Peruano. № 185. 1952. Digitalización: Catálogo Arquitectura Movimiento Moderno Perú. 
os

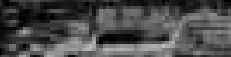

thencon

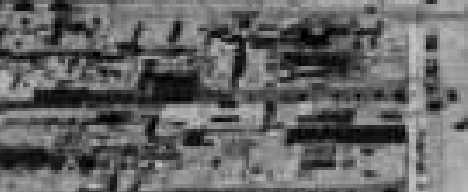

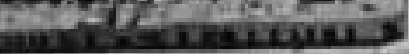

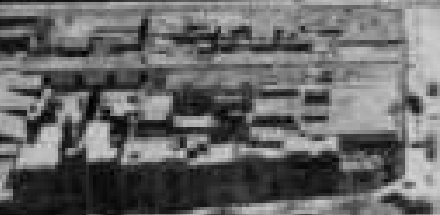

Estadio Nacional. Lima. 1952. Alberto Jimeno. Vista aérea general.

Fuente: Revista El Arquitecto Peruano. $N^{\circ}$ 185. 1952. Digitalización: CAMMP

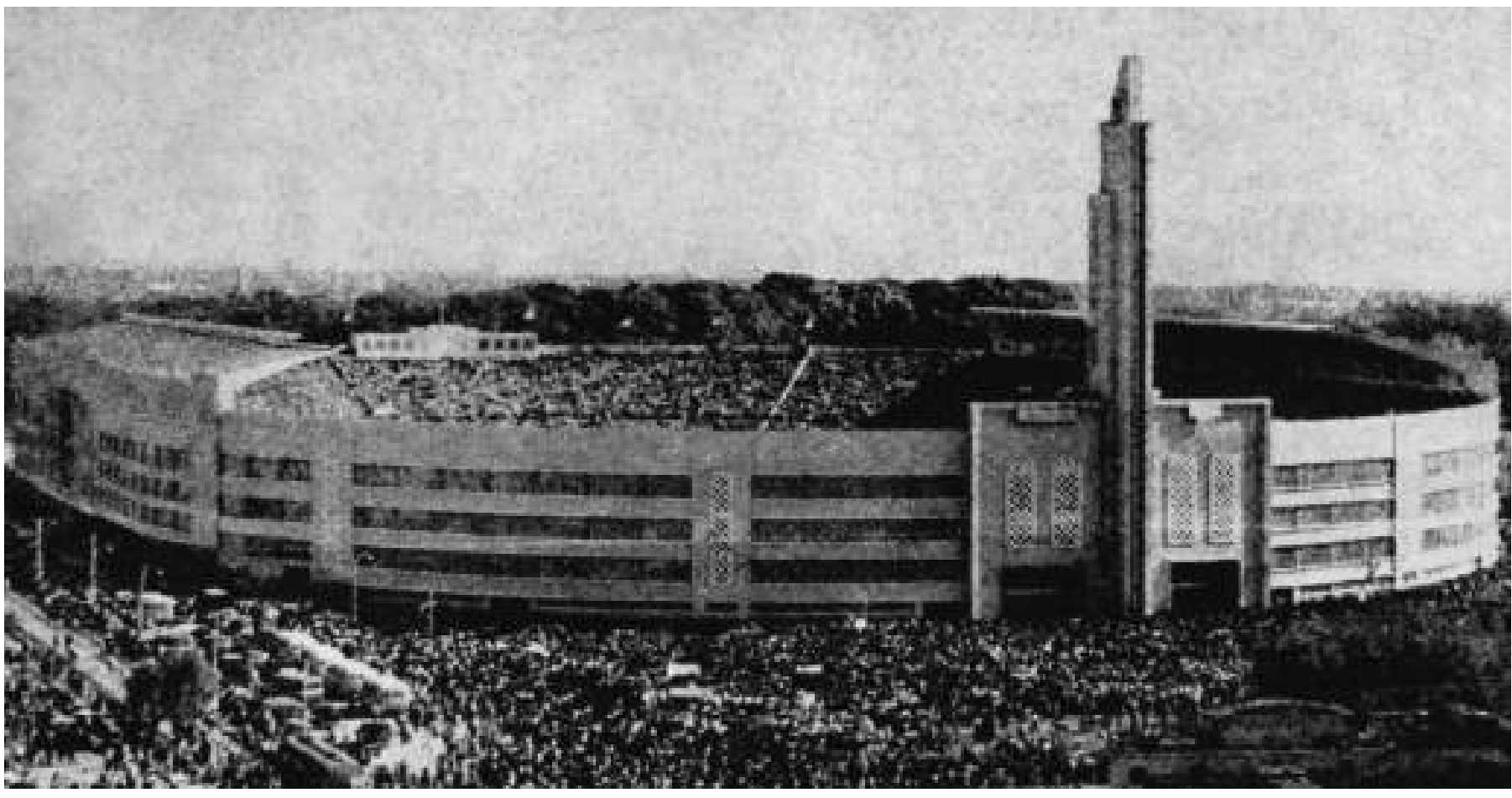

Estadio Nacional. Lima. 1952. Alberto Jimeno. Vista de la inauguración.

Fuente: Revista El Arquitecto Peruano. № 185. 1952. Digitalización: CAMMP 


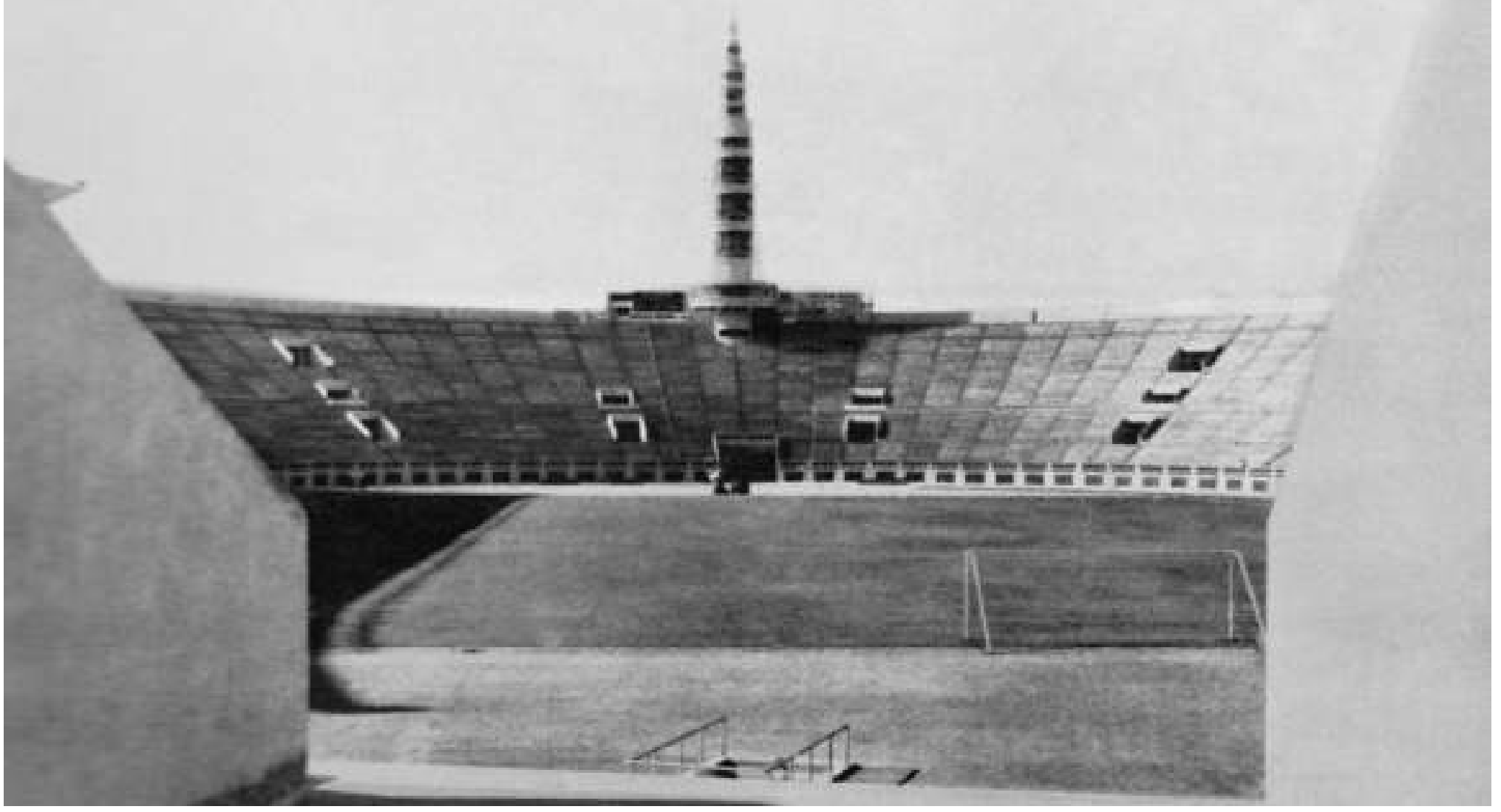

Estadio Nacional. Lima. Vista de la tribuna norte. Fuente: Revista El Arquitecto Peruano. №. 185. Digitalización: CAMMP.

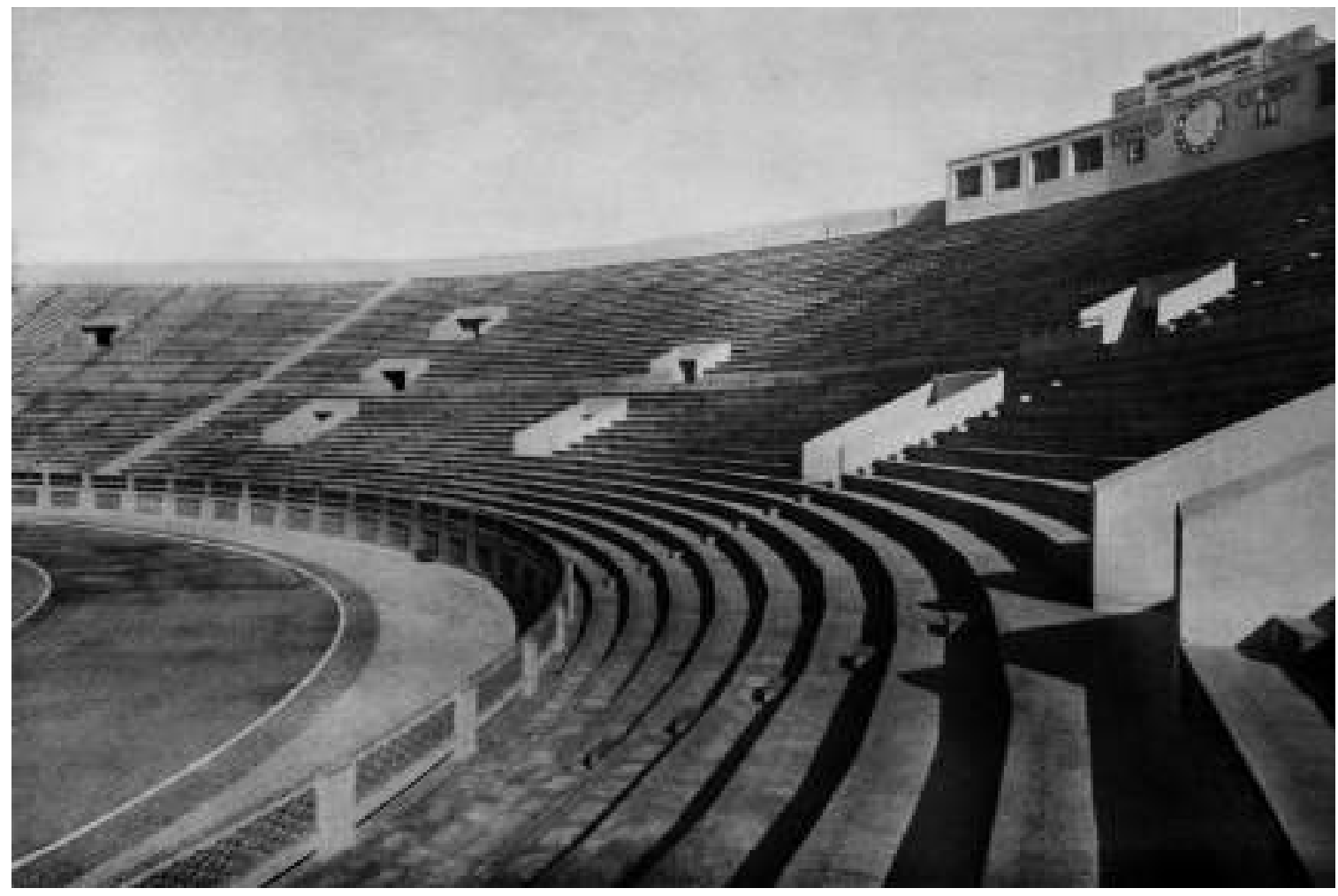

Estadio Nacional. Lima. Tribuna sur. Fuente: Revista El Arquitecto Peruano. № 185. 1952. Digitalización: CAMMP. 


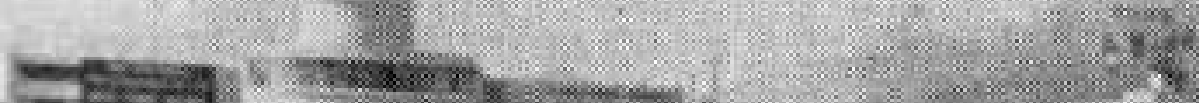

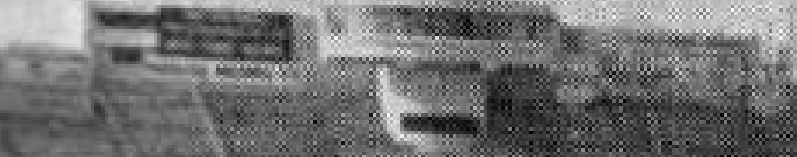

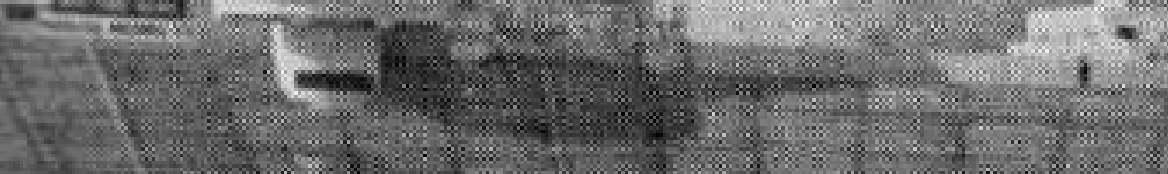
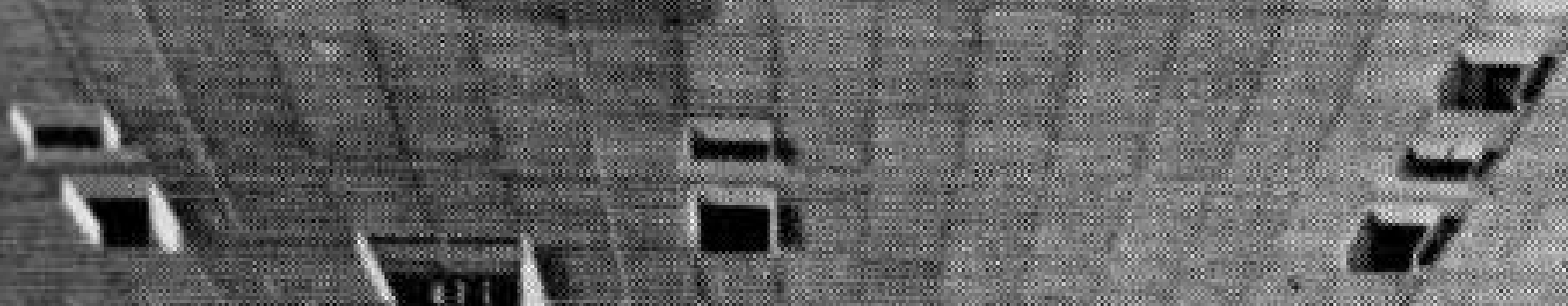

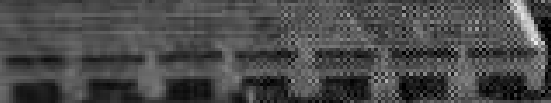

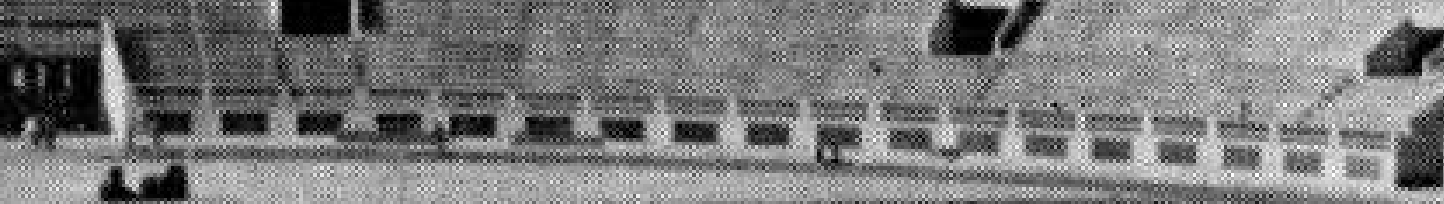

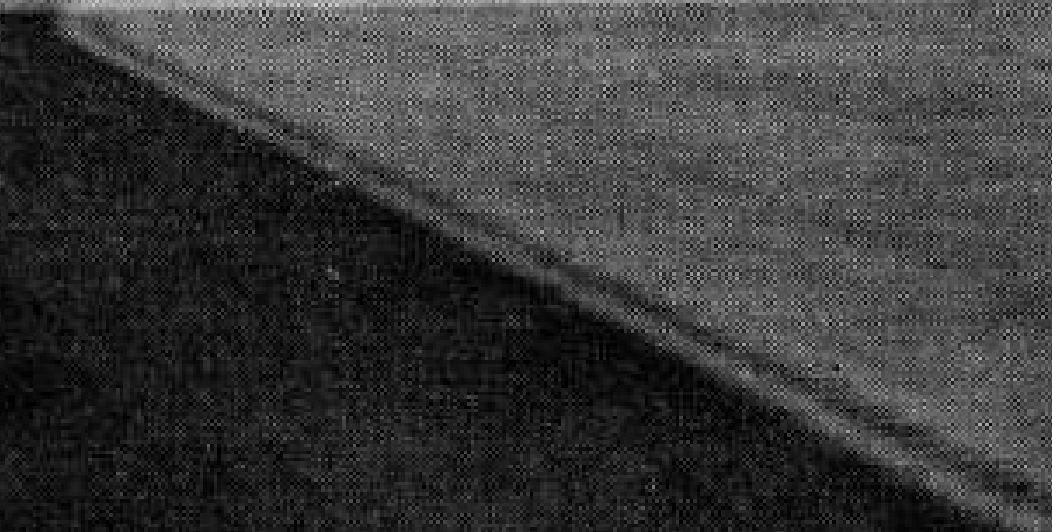

20

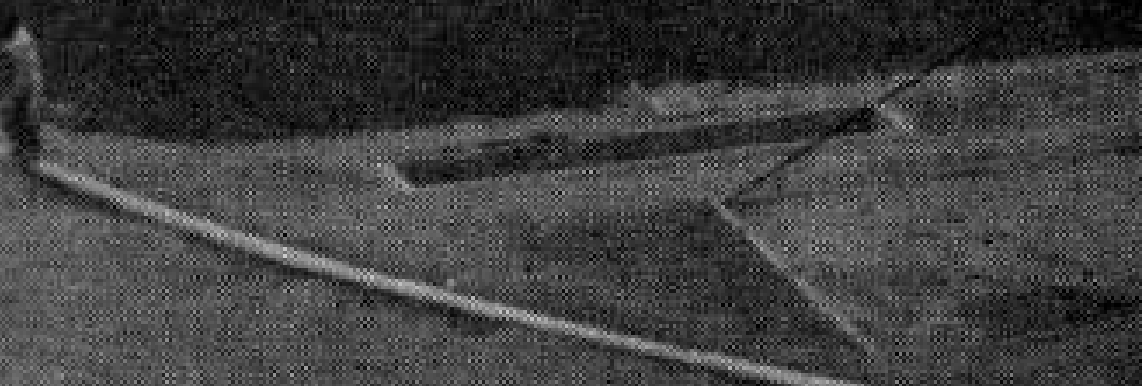




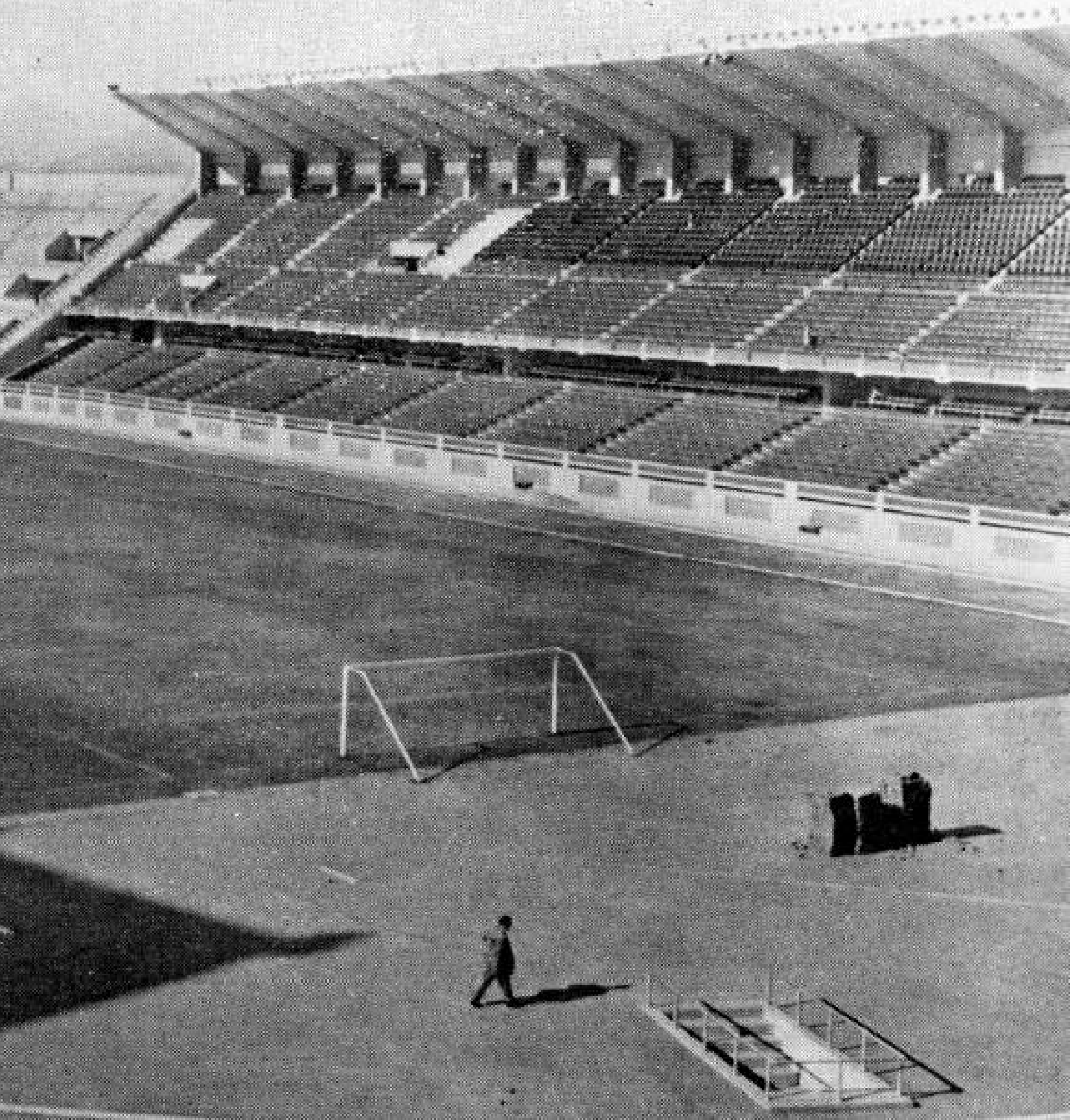




\section{ARQUITEXTOS}

ISSN 1819-2939

Año 26, № 34, enero-diciembre de 2019
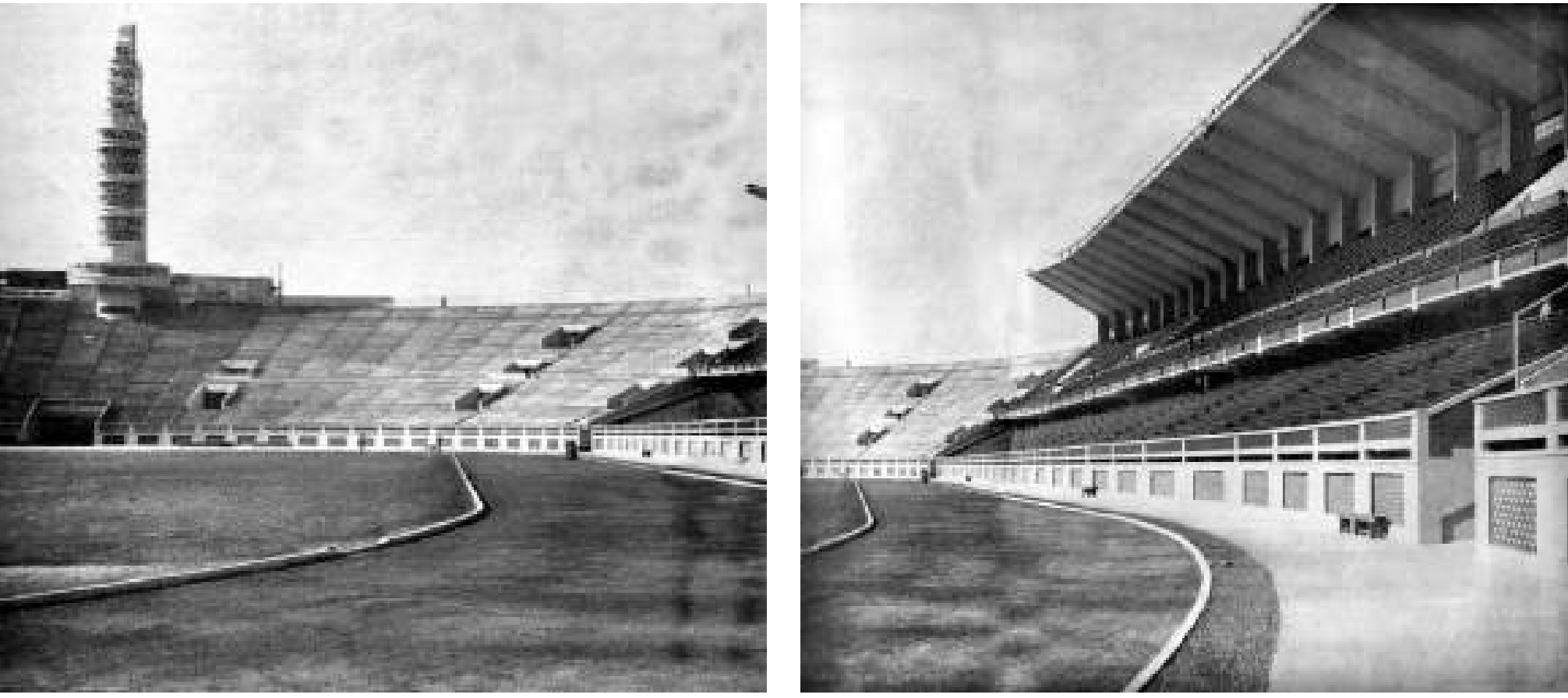

Estadio Nacional. Lima. Vistas de la pista atlética y de la tribuna de oriente. Fuente: Revista El Arquitecto Peruano. No 185.1952.

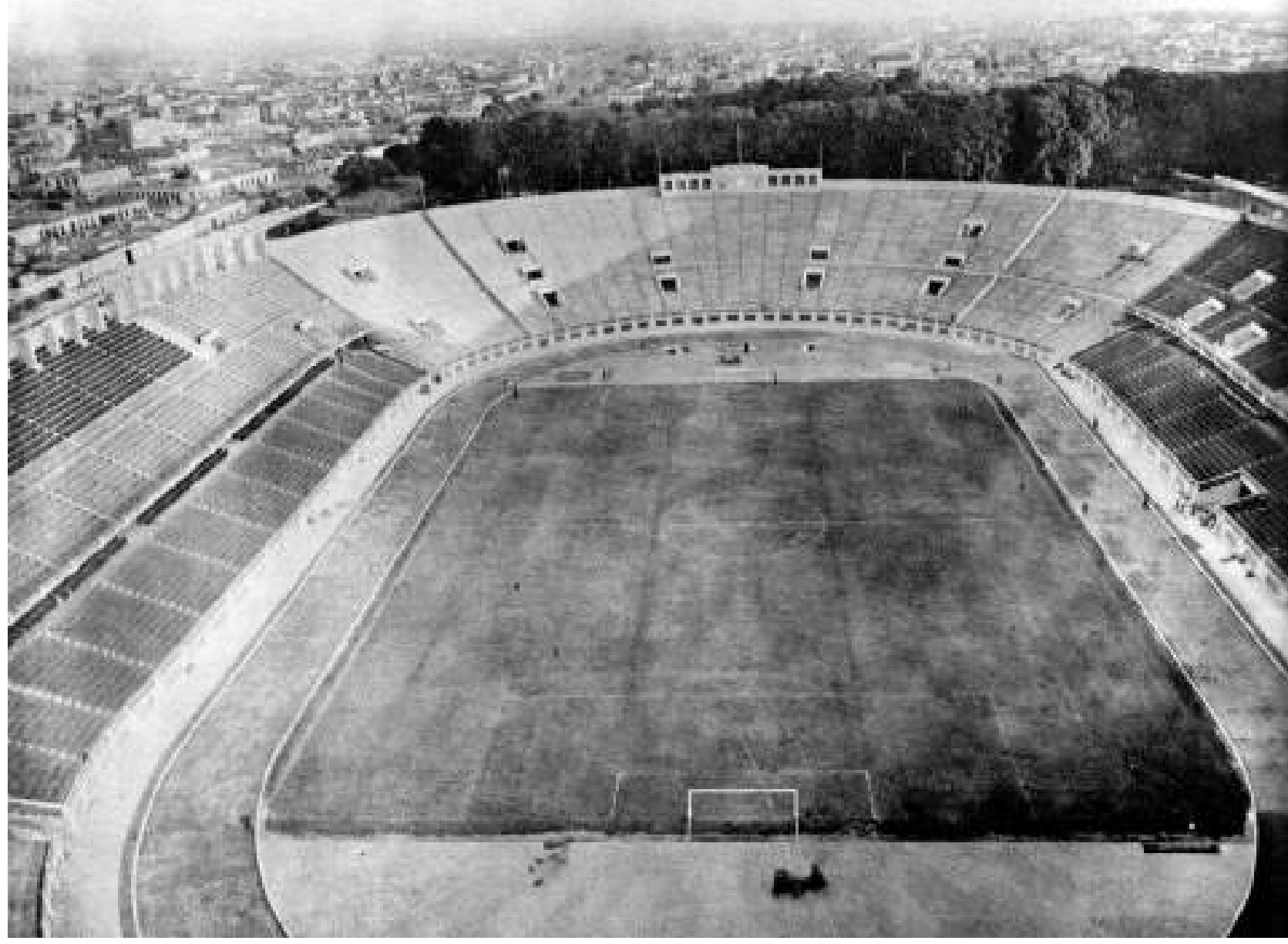

Estadio Nacional. Lima, 1952. Vista desde la torre de la cancha de fútbol hacia la tribuna sur. Fuente: Revista El Arquitecto Peruano. No 185. 


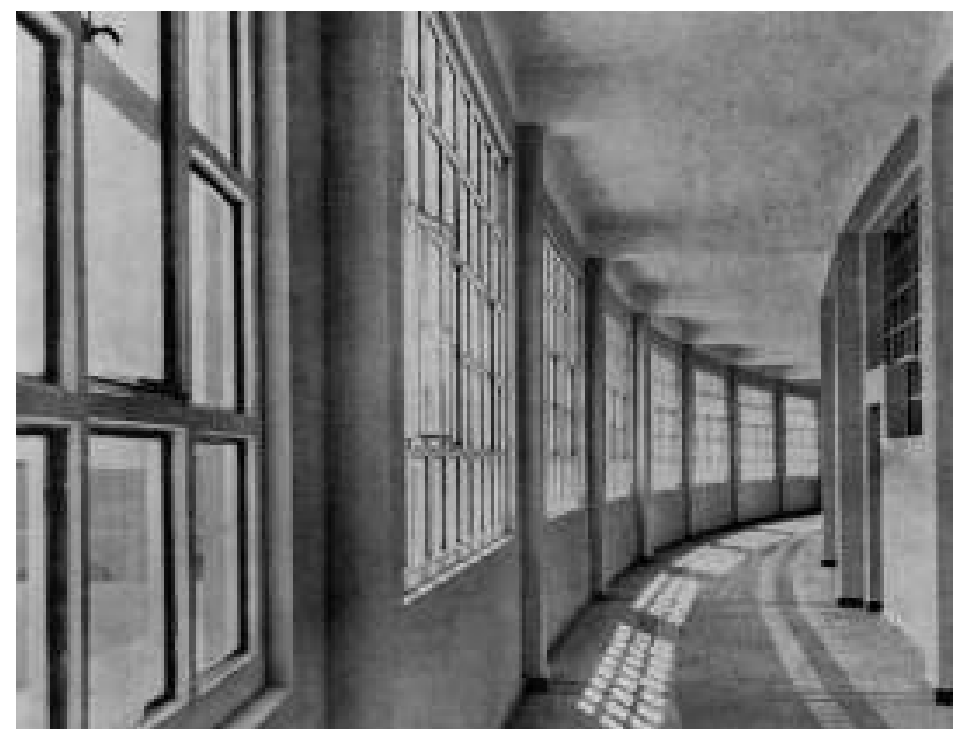

Estadio Nacional. Lima. Vista del corredor perimétrico.

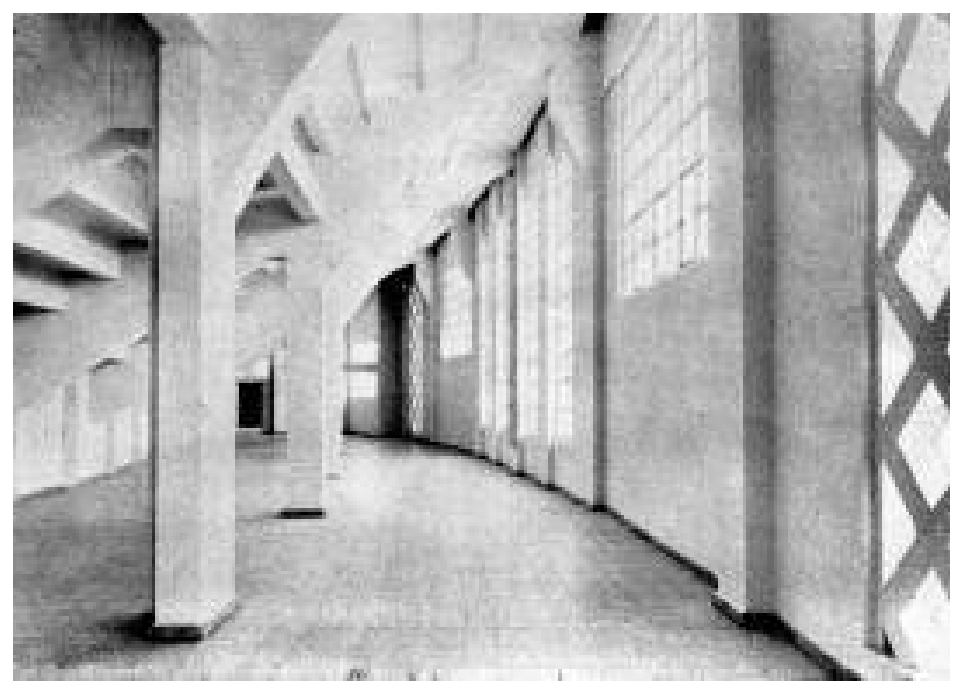

Estadio Nacional. Lima. Circulación interior de la tribuna sur.

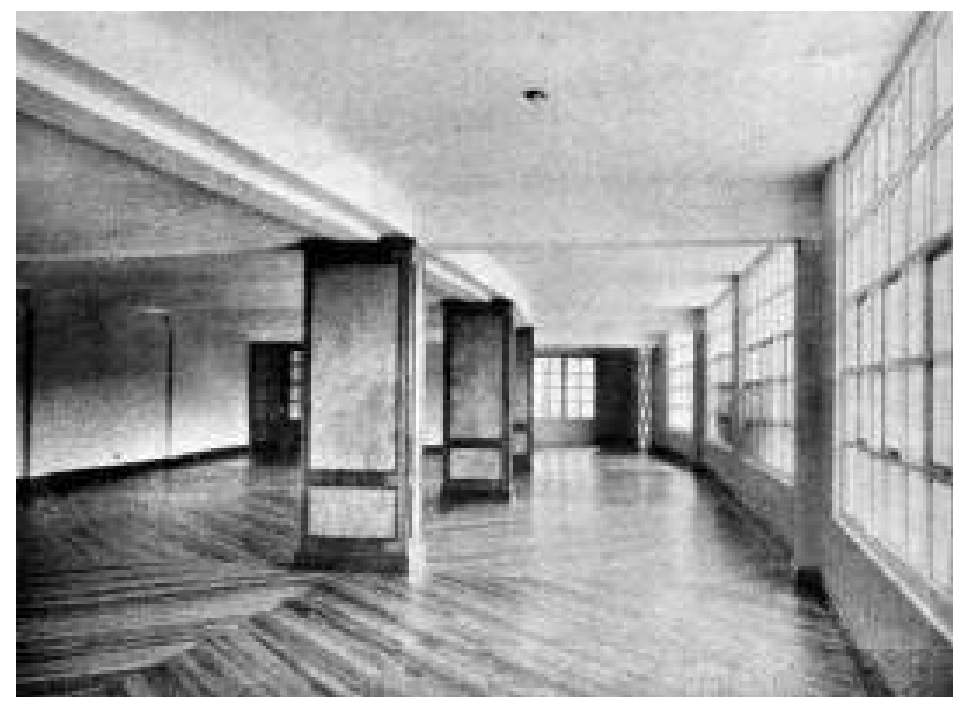

Estadio Nacional. Lima. Vista interior.

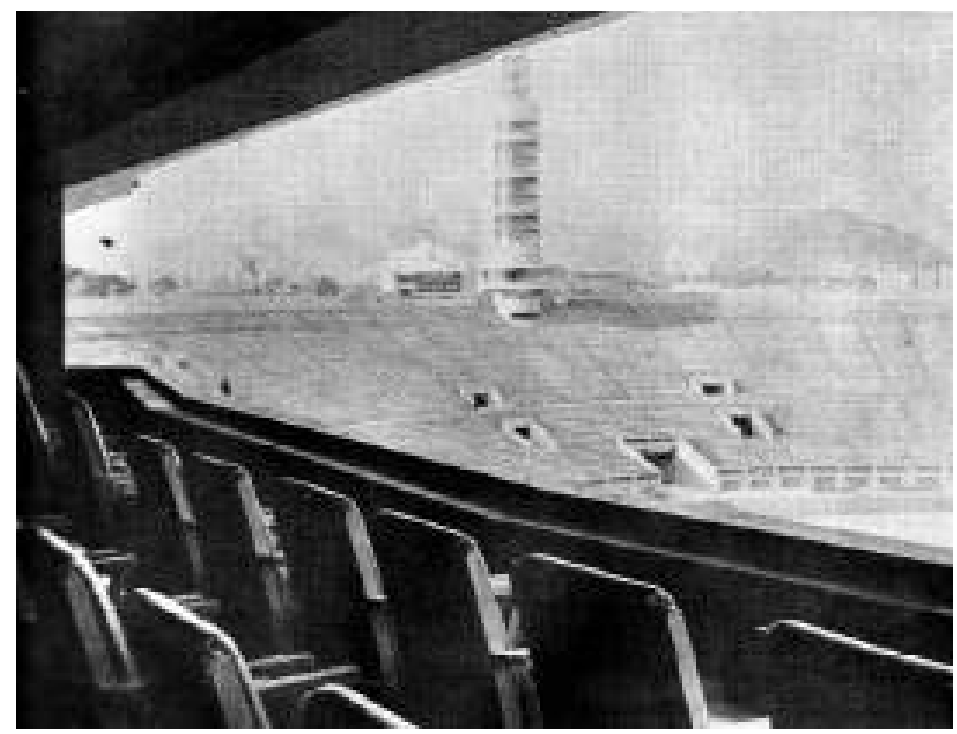

Estadio Nacional. Lima. Vista desde el palco presidencial.

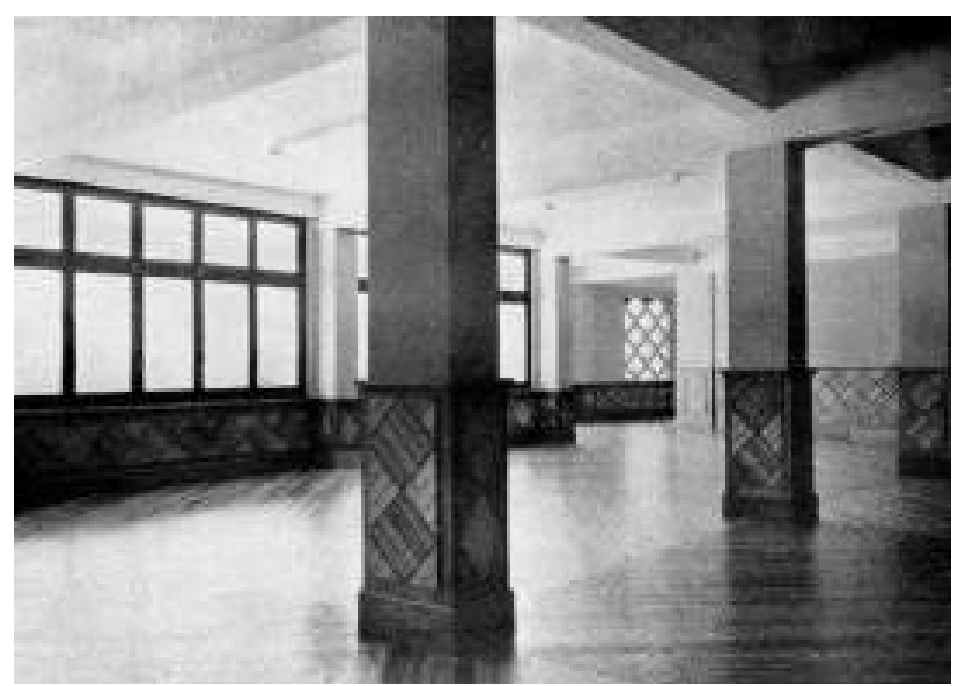

Estadio Nacional. Lima. Vista interior de la tribuna sur.

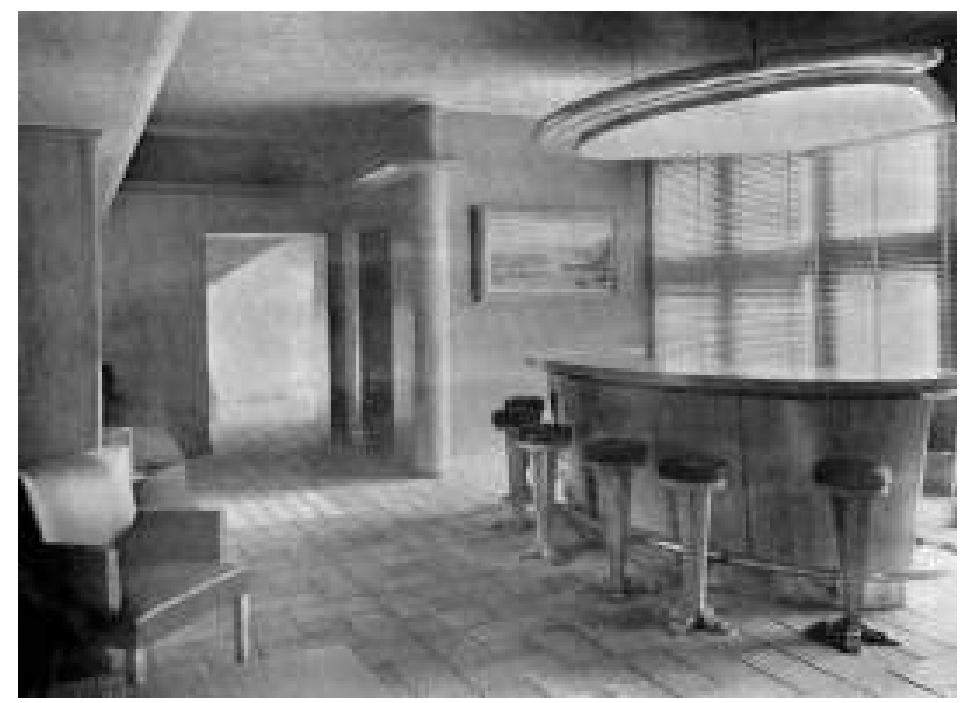

Estadio Nacional. Lima. Bar del palco presidencial. Fuente: Revista El Arquitecto Peruano. Nº 185. 1952. Digitalización: CAMMP. 


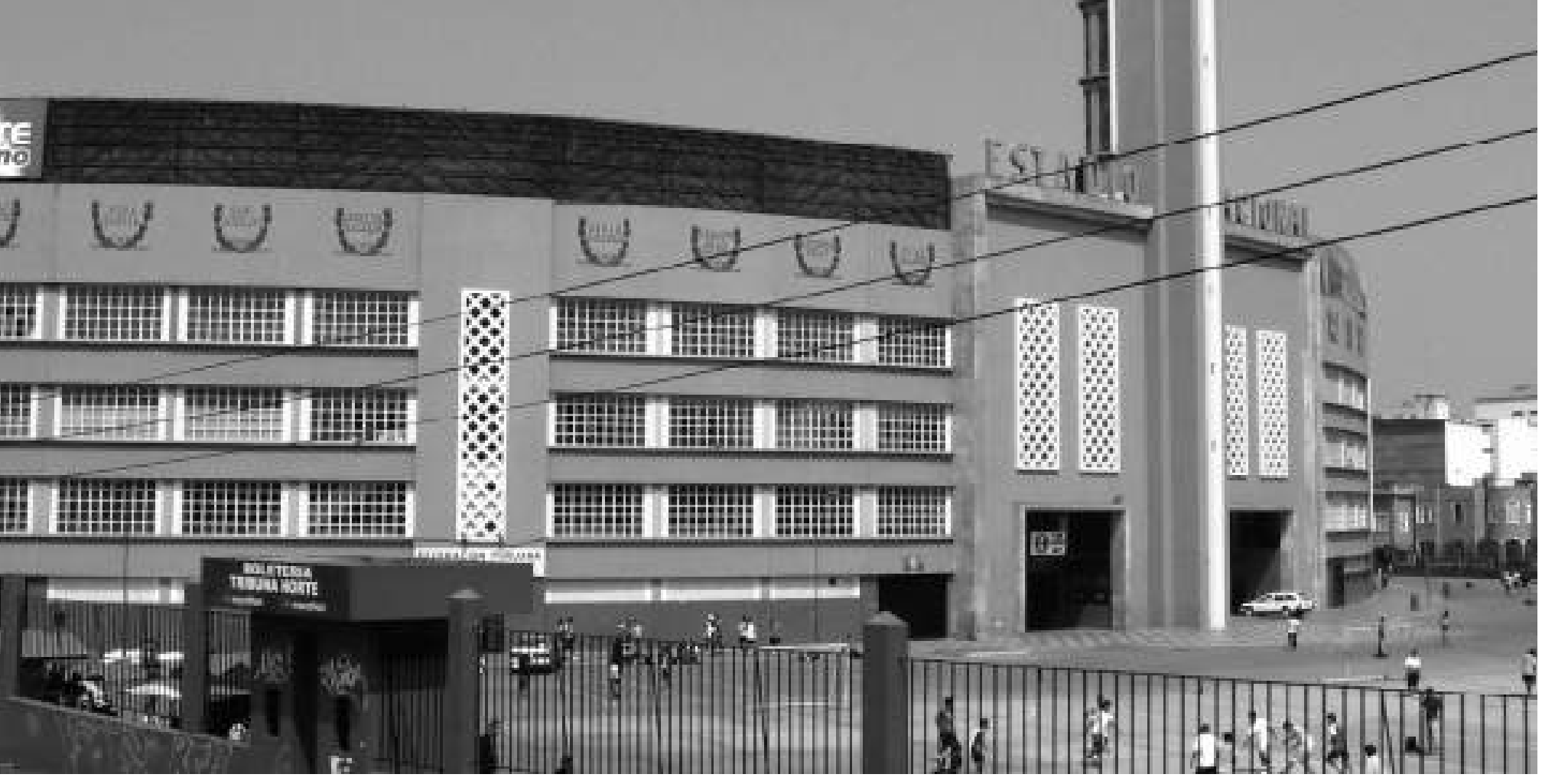

Estadio Nacional. Lima. Diseño y construcción: 1950 - 1952. Foto: E. Martuccelli. 2006

a cargo de la empresa Cillóniz - Olazabal - Urquiaga S.A. (Acevedo, Llona, 2016, p. 104)

Otro estadio de gran envergadura fue construido durante el gobierno de Odría: el estadio de la Universidad Nacional Mayor de San Marcos, con una capacidad incluso más grande. Dicho estadio era un viejo proyecto que venía desde 1938, que se había detenido por considerarse alejado de la ciudad, en una zona de gran riqueza arqueológica. El estadio se retoma en 1950, a la par que se proyecta la nueva ciudad universitaria, inaugurándose en mayo de 1951 (Álvarez, 2007, p. 71, 72)

El mismo año, el Estadio Nacional inició su transformación, edificándose la tribuna sur que no existía, para reconstruir paulatinamente las otras tres. Se resolvieron problemas de agua, desagüe y luz, se adecuó el entorno a las necesidades de un gran recinto deportivo, lo que determinó el ensanche de calles aledañas.
La inauguración del nuevo Estadio Nacional tuvo lugar el 27 de octubre de 1952. La planta elíptica del estadio contrasta con la portada de ingreso de occidente y su gran hall preferencial, así como la esbelta torre de transmisiones, al norte, que constituye un hito urbano. La cancha de fútbol oficial vino rodeada de una pista atlética. Todos los servicios necesarios fueron considerados en el plano original: boleterías, oficinas, gimnasios, camerinos, depósitos, servicios higiénicos. Incluso tiendas, bares y restaurante. El enorme espacio debajo de las tribunas, correspondiente a edificios de 4 pisos de altura, fue ocupado durante décadas por diversas federaciones deportivas.

Varias páginas de la revista El Arquitecto Peruano fueron dedicadas al estadio al momento de su inauguración. Espléndidas fotos en blanco y negro dieron cuenta de su solidez y organización espacial. 
... ha sido terminada en su casi totalidad la edificación del nuevo gran Estadio Nacional, que presenta un monumental y bello aspecto visto desde el exterior y desde cualesquiera de sus instalaciones interiores $/ . . . /$... que habrá de ubicarlo como una de las construcciones deportivas más sugerentes del continente $y$, sin hipérbole, uno de los más completos y hermosos en su género. (Anónimo, 1952, p. 22)

El texto presenta las virtudes arquitectónicas del estadio, desde su magnitud y su comodidad. También hace hincapié en los retos estructurales que tuvieron que resolverse, es decir, el estadio como una gran obra de ingeniería. Para eso se calculó un complejo sistema de pórticos preparados para resistir espectáculos masivos, que tuvieran la relación adecuada a las cargas de las tribunas y a la resistencia de los volados. Las consideraciones incluían los riesgos propios de sismos y vientos.

Los estadios Nacional y San Marcos fueron un ejemplo del gigantismo que se buscaba en este tipo de edificaciones, que tuvo en el estadio Maracaná de Río de Janeiro (inaugurado en 1950 y con capacidad para 200 mil personas) su mejor ejemplo. También, que este tipo de obras era imposible sin la participación del Estado, facilitando los terrenos, apoyando con parte de las obras o costeándolas en su totalidad. Los gobiernos populistas apoyaron decididamente la construcción de estos recintos cuando incorporaron el deporte a las políticas sociales y aprovecharon las victorias logradas en la competencia. (Álvarez, 2007, p. 72)

Desde el Campeonato Sudamericano de fútbol de 1953, el Estadio Nacional, en su tercera versión, albergó importantes partidos durante casi 60 años. La tragedia ocurrida en mayo de 1964 planteó la necesidad de reducir su capacidad a aproximadamente 45000 espectadores, que es como se mantuvo durante décadas.

Por cuestiones de accesibilidad y también de seguridad se planteó su remodelación en el segundo gobierno de Alan García. En esta cuarta versión, volvió a reducir su capacidad en las graderías y se agregaron palcos en toda la parte superior de las tribunas. El diseño del proyecto fue de José Ben- tín Diez Canseco, Luis Solari Lazarte, Mario López Marsili y César Valdez Flores. Uno de los propósitos principales parece haber sido transformar el exterior, agregando una estructura metálica convexa, que apenas respetó la torre de comunicaciones. La reinauguración, con nueva imagen, se realizó el 24 de julio de 2011: desde entonces, el estadio ofrece a la ciudad una fachada curva y luminosa.

\section{Arquitectura deportiva en Latinoamérica. Tres casos emblemáticos}

En el movimiento moderno latinoamericano, resalta un ejemplo temprano y singular: el Estadio Centenario de Montevideo, construido para la Copa Mundial de Fútbol de 1930. Diseñado por los arquitectos Juan Scasso y José Domato, su nombre hace referencia a las celebraciones del centenario de la independencia en Uruguay.

Con la poca experiencia que había entonces de construir edificios de esta envergadura, el estadio se hizo realidad en pocos meses. Se decidió hacerlo en las afueras de la ciudad, aprovechando los taludes naturales del área donde fue ubicado, para una capacidad de aproximadamente 70,000 espectadores. Uno de los elementos más originales del estadio es la "torre de los homenajes", un esbelto mirador hacia el interior del estadio y hacia la ciudad, cuya base imita las alas de un avión y la proa de un barco. Es decir, el diseño resolvió todas las demandas funcionales que un edificio así implica, aunque la simplicidad de la propuesta no renunció a la expresividad que un monumento así encarna, concentrándose en la torre, convertida en hito de la ciudad. (Spósito, 2006) Juan Scasso fue también, coincidiendo con Alberto Jimeno, un reconocido diseñador de infraestructura educativa.

El estadio no pudo terminarse para los primeros partidos de la Copa Mundial y fue inaugurado, aún inconcluso, el 18 de julio de 1930, con el partido entre Uruguay y Perú, La final de dicho certamen enfrentó al dueño de casa con Argentina, siendo Uruguay el primer campeón del mundo.

El Estadio Centenario de Montevideo fue declarado en 1983 por la FIFA "monumento 

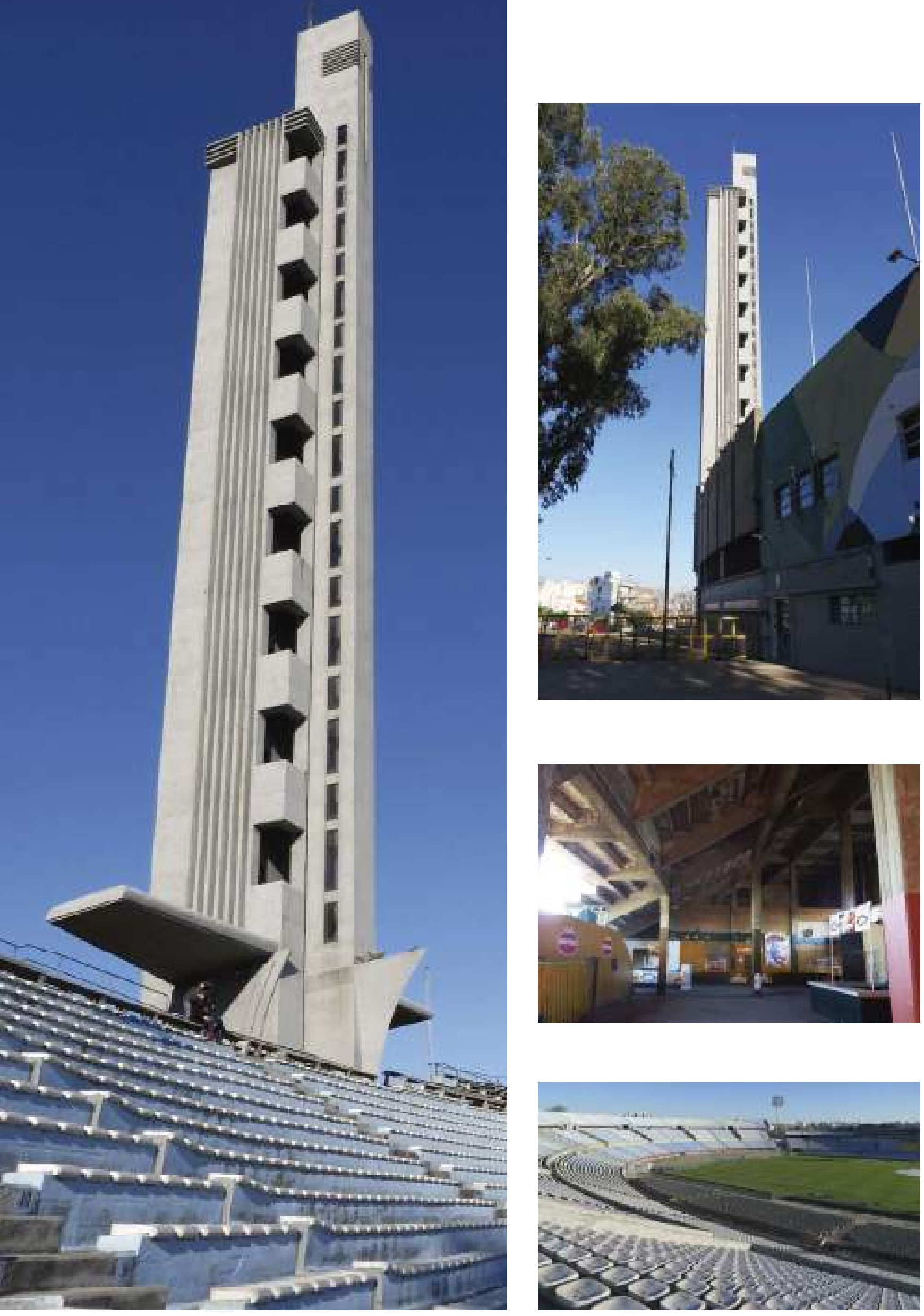

Estadio Centenario. Montevideo. Arquitectos Juan Scasso. José Domato, 1930.

Vistas exteriores e interiores. Fotos: Elio Martuccelli, 2013. 


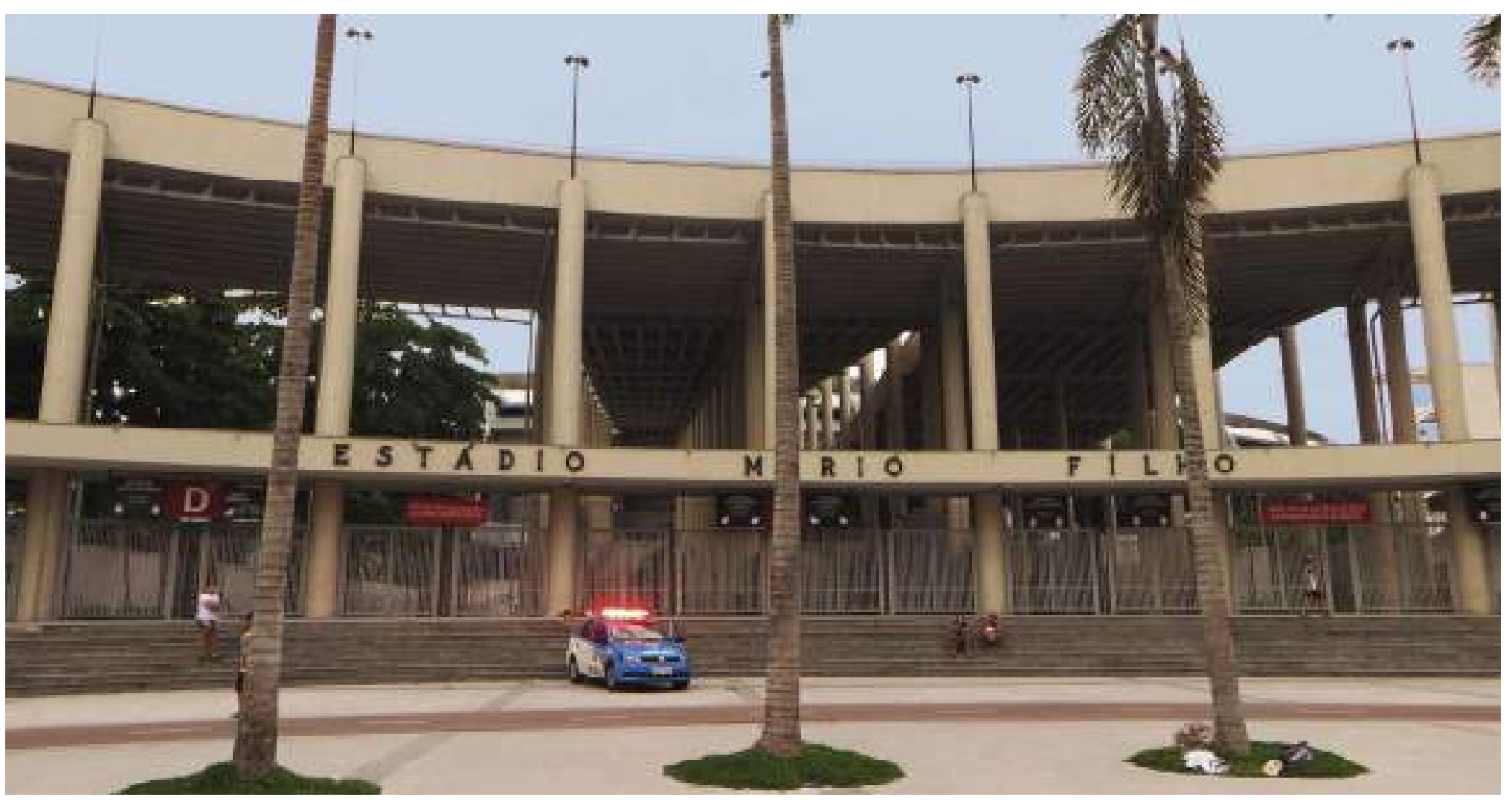

Estadio Maracaná. Río de Janeiro. 1950. Foto: César Castañeda. 2015

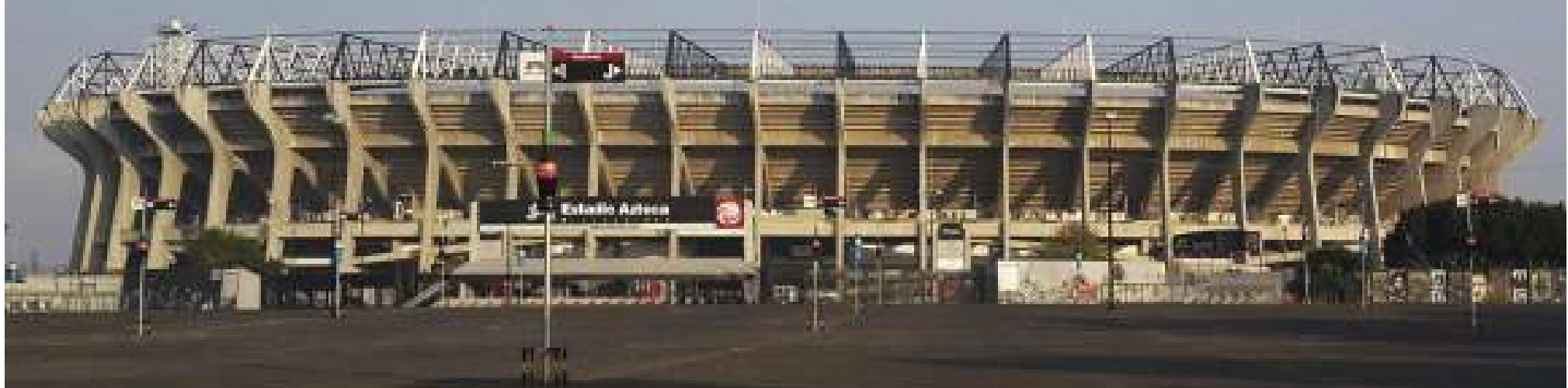


histórico del fútbol mundial"1. Es considerado como uno de los estadios más importantes en el desarrollo deportivo de Sudamérica y del mundo, no solo por su importancia histórica, valor estilístico inspirado en el expresionismo alemán (Carmona, 2012), dimensión inusual para la época, innovación y aporte tecnológico en cuanto a materiales y proceso constructivo, sino también por su presencia icónica en la ciudad y ser un referente para la comunidad uruguaya y para el mundo. Sin embargo, hay un debate en torno a su demolición para construir un nuevo estadio que cumpla con la normativa actual de la FIFA.

En la historia de la infraestructura deportiva latinoamericana, otro ejemplo excepcional lo constituye el Estadio Mario Filho - Maracaná de Río de Janeiro. El proyecto, diseñado por un equipo de arquitectos brasileros, fue escogido por concurso nacional y responde a un programa grandioso. Su expresión formal mantiene gran sintonía con la solución estructural, donde destacan los nervios y la marquesina. (AA VV, 2000) Fue inaugurado en 1950 para la Copa Mundial de dicho año, a cuya final asistieron más de 200000 espectadores, una cifra que sigue siendo la más alta registrada en un partido de fútbol. Aquel día Brasil perdió ante Uruguay.

Tuvo modificaciones a lo largo de las décadas, en el año 2002 fue declarado como Patrimonio Nacional y sin embargo, volvió a ser remodelado entre 2010 y 2013 para la Copa Mundial de $2014 .^{2}$ En esta última remodelación buscó mantener las características principales con las que fue construido en 1950, sin el deseo de sustituirlo. En el fondo, había la necesidad de renovarlo, pero sin borrar su imagen original. Entonces, redujo una vez más su capacidad, a 80000 espectadores, para lo que se demolieron tribunas para mejorar la visibilidad. Se agregó una nueva cobertura fotovoltaica: un gran anillo que contiene paneles solares para producir energía. Su imagen, vista desde arriba, es distinta al estadio original, pero desde el exterior la cobertura no se ve, por lo que su elevación se mantiene. La fachada, protegida por el Instituto Nacional de Patrimonio Histórico y Artístico, se ha conservado (Fer- nandes Arquitetos Associados, 2019) y, por afuera, el Maracaná sigue prácticamente intacto permitiendo su lectura original y manteniendo la memoria de la ciudad. También fueron conservadas las principales circulaciones internas y la estructura existente.

El reto de la última remodelación fue, a la vez, mejorar y preservar el Maracaná manteniendo su imagen y haciendo que el edificio construido para la Copa de 1950 vuelva a ser uno de los principales estadios del mundo.

Por último, el Estadio Azteca, conocido como el coloso de Santa Úrsula, está ubicado en la Ciudad de México, es un recinto que también está cargado de significados para el fútbol sudamericano y mundial. Se planificó con el objetivo de que México pudiera obtener la sede de la Copa Mundial de Fútbol de 1970.

Se convocó a un concurso arquitectónico para la realización de la obra, al que fueron invitados algunos arquitectos. El programa arquitectónico apuntaba a una capacidad no menor de 100 mil espectadores, para los que había que resolver correctamente los accesos, la visibilidad y la comodidad. El proyecto ganador fue de los arquitectos $\mathrm{Pe}$ dro Ramírez Vázquez y Rafael Mijares, superando la propuesta de Félix Candela. Inició su construcción en 1962, fue inaugurado en 1966 y fue sede principal en los Campeonatos mundiales de fútbol de 1970 y 1986.

Su construcción fue una proeza tecnológica para la época pues fue necesario excavar 180 millones de kilogramos de roca para emplazarse, pues el terreno no era estable; asimismo, para solucionar el estacionamiento. (Suárez Argüello \& Sánchez Andrés, 2017)

El edificio ostenta grandeza y poder sin perder la esbeltez de una estructura ligera, la fachada está constituida por columnas de concreto reforzado que soportan las graderías estableciendo un ritmo continuo.

A pesar de ser un edificio emblemático diseñado por uno de los padres de la arquitectura moderna mexicana, este no se encuentra declarado ni figura registrado en el Catálogo Nacional de Monumentos Históricos Inmuebles - INAH, actualizado al 2019, de la Secretaría de Cultura del Gobierno mexicano. El Estadio Azteca ha sido objeto 
de nueve remodelaciones a lo largo de las décadas hasta el día de hoy. Como en otros estadios, se ha reducido su capacidad por motivos de seguridad, albergando actualmente 87,000 espectadores. La última intervención ha alterado la funcionalidad del estadio al instalar estructuras internas que soportan las ampliaciones obstruyendo la visión, característica fundamental del edificio original que permitía una lectura limpia de la cancha en 360 grados desde cualquier punto en las tribunas y palcos. Sin embargo, las remodelaciones han respetado la lectura exterior del edificio y la escultura de Alexander Calder ubicada en el ingreso principal.

\section{Reflexiones finales. Patrimonio moderno en Latinoamérica y Perú}

Cada país del continente, a través de instituciones y organizaciones, valora lo que en sus ciudades se ha construido: en este caso nos referimos a lo que corresponde al siglo $X X$. Eso tiene que ver con un trabajo de documentación y conservación que según los países se realiza en mayor o menor medida, con mejores o peores resultados.

El reconocimiento de una obra arquitectónica o urbana a nivel mundial es un proceso con una serie de requisitos, basado en criterios de valor. El proceso comienza con los inventarios y catálogos nacionales, para pasar a las listas indicativas que cada país hace llegar como nominaciones a la lista de patrimonio mundial de la UNESCO. (Conti, 2015) Algunos edificios y conjuntos urbanos del movimiento moderno latinoamericano han logrado su inscripción en dicha lista, aunque resultan en porcentaje una pequeña minoría. Para llegar aquí, las obras deben tener un valor universal excepcional. ${ }^{3}$

No aparecen en la lista de la UNESCO ninguno de los tres estadios mencionados en el artículo (el Centenario, el Maracaná y el Azteca) así como ningún edificio latinoamericano dedicado al deporte. Lo cierto es que, en general, tampoco abundan en la lista del patrimonio mundial demasiadas obras del siglo XX. ${ }^{4}$

El Estadio Nacional en Lima no cuenta con protección del Ministerio de Cultura como bien integrante del Patrimonio In- mueble Nacional, y luego de la remodelación del 2011 para adecuarlo a las nuevas normativas estructurales y de la FIFA dejó de ser un ejemplo representativo del movimiento moderno. En la memoria descriptiva del proyecto de remodelación, de los arquitectos Bentín, López, Valdez y Solari, llama la atención encontrar que una de las premisas fuera "rescatar y revalorar los elementos conceptuales y más arraigados en la memoria colectiva de los peruanos que posee el estadio" (Archivo BAQ Arquitectura Panamericana, 2019).

Si bien su corazón de concreto armado aún se mantiene en el interior, su imagen externa es radicalmente distinta. La intervención consistió en revestir completamente el edifico con una membrana "inteligente" ocultando por completo la fachada original del estadio. Su remodelación estuvo planteada en sentido inverso a lo que se realizó en el Maracaná. Si en el ejemplo carioca se logró renovarlo por dentro y preservarlo por fuera, en el caso limeño se mantuvo buena parte del interior y se transformó el exterior.

El Estadio Nacional es un ejemplo más de los muchos hitos arquitectónicos del siglo XX que en el Perú se han perdido en los últimos años, sobre todo en su imagen externa. Si este ya no puede ser conservado, otros edificios aún podrían mantenerse fieles a como fueron concebidos y construidos. En el rubro de la arquitectura deportiva nacional del siglo pasado algunos están plenamente identificados y son ejemplos significativos que podrían conservarse. ${ }^{5}$

Aun cuando no se reconoce plenamente la condición patrimonial de las obras modernas en el país y su valoración sea débil por parte de la comunidad en su conjunto, hay iniciativas especializadas que buscan la declaración de algunos edificios del movimiento moderno peruano como monumentos históricos. ${ }^{6}$

Tratándose de un patrimonio reciente, la situación en la que se encuentra cada edificio es crucial para su posible protección. Son varios los problemas a enfrentar: uno podría ser el propio material de construcción que, al cabo de algunas décadas, comienza a mostrar deficiencias. En otros 
casos, los edificios se encuentran en pleno uso, para lo que fueron diseñados o acaso para otra función: no están vacíos. Otros no cumplen estándares contemporáneos y su transformación es, si desean seguir funcionando, una necesidad legal.

En el caso particular de los estadios, surge la duda si estos deben conservarse tal como fueron inaugurados. Las necesidades deportivas, evidentemente, van cambiando a través de las décadas y las instalaciones pueden mostrar deficiencias con el tiempo. Tal vez algunos merecen mantenerse con prudentes modificaciones, otros casos no lo ameritan y son necesarias transformaciones más profundas. Mucho tiene que ver el significado y el carácter simbólico que los estadios hayan logrado adquirir en la sociedad, así como su condición de hitos urbanos con valor histórico.

Cada caso es singular y el patrimonio es también un concepto en transformación, más aún cuando se trata de declarar monumentos históricos a algunos edificios del siglo XX. Lo cierto es que el reconocimiento que puedan lograr algunos de ellos servirá para entender y valorar mejor, como sociedad, el ámbito en el que vivimos.

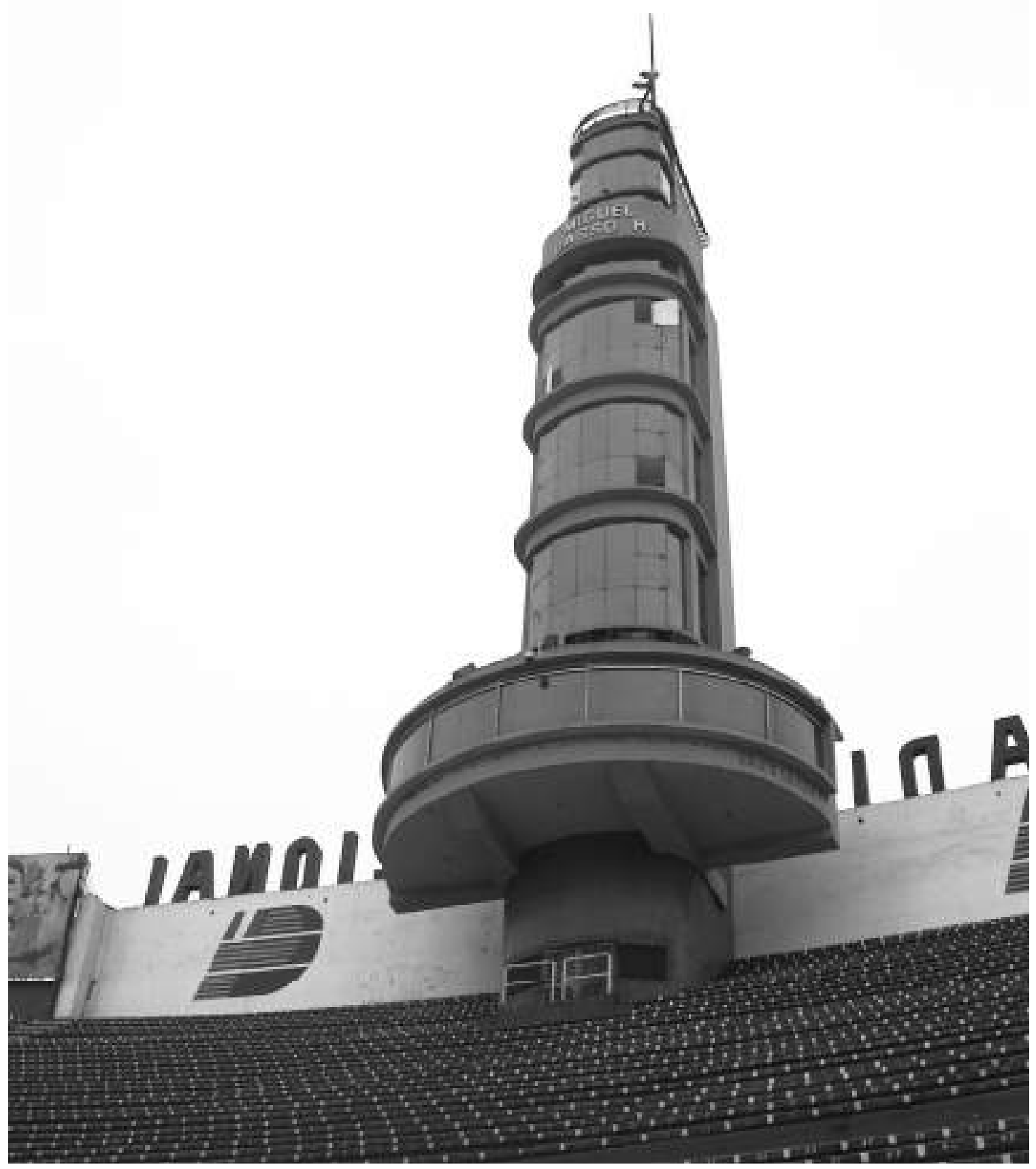




\section{Notas}

1 Montevideo cuenta con una Guía Arquitectónica y Urbanística editada por la Junta de Andalucía y publicada en 1992 donde se listan 40 obras modernas. El Estadio Centenario aparece dentro de la categoría Obras Modernas Ortodoxas y figura como Monumento Histórico Nacional (MHN) desde 1989 y Bien Histórico Municipal (BHM). La ficha que corresponde al edificio es la D-06 (Junta de Andalucía Consejería de Vivienda y Ordenación del Territorio, 1992, pág. 426). Si bien la guía antes mencionada lo cataloga como MHN, al hacer la búsqueda de la Resolución de Declaración no figura en el listado descargable de bienes inmuebles y muebles declarados Ley 14.040, actualizado en octubre 2019, de la página del Ministerio de Educación y Cultura de Uruguay (Comisión del Patrimonio Cultural de la Nación, 2019).

2 El Estadio Maracaná, fue declarado Patrimonio Nacional en el año 2002 junto con los otros edificios que integran el complejo deportivo existente, que comprende el Gimnasio Gilberto Cardoso (Maracanãzinho), el Estadio Célio de Barros y el parque acuático Júlio Dellamare a través del Decreto $\mathrm{N}^{\circ}$ 21677 del 3 de julio de 2002 (Leis Municipais do Rio de Janeiro, 2019). El emblemático edificio figura en la Guia do Patrimônio Cultural Carioca Bens Tombados 2014 (Prefeitura do Rio de Janeiro / Patrimônio Cultural, 2014).

3 La lista del patrimonio mundial fue creada por la UNESCO en 1972, actualizándose anualmente. Desde 1992 buscó asesoramiento en el DoCoMoMo para incluir obras del movimiento moderno. Es decir, el DoCoMoMo internacional guarda vínculo con la UNESCO para incorporar obras del movimiento moderno a la lista del patrimonio mundial. Las obras latinoamericanas del siglo XX que figuran son:

Dos viviendas: la casa - estudio de Luis Barragán en México DF y la casa Currutchet en La Plata, Argentina, como integrante de 17 obras de Le Corbusier (en distintas partes del mundo) reconocidas con ocasión de los 50 años de su fallecimiento.

Tres grupos de edificios: el campus universitarios de la UNAM, en México DF; el campus de la Universidad Nacional de Caracas, Venezuela; el conjunto arquitectónico moderno de Pampulha, en Belo Horizonte, un grupo de obras notables diseñadas por Oscar Niemeyer al inicio de su carrera.

Asentamientos industriales, con sus respectivos pueblos aledaños: las oficinas salitreras de Humberstone y Santa Laura y la ciudad minera de Sewell, ambos en Chile, construidos entre los siglos XIX y XX; el complejo industrial de Fray Bentos en Uruguay.

Entornos urbanos: el barrio histórico de la ciudad portuaria de Valparaíso, Chile, que aunque tiene su origen en el período colonial, buena parte de su estructura urbana y edificios corresponden al siglo XX; el paisaje cultural de Río de Janeiro, considerando las áreas costeras de la ciudad ubicadas entre las montañas y el mar, enriquecidas notablemente por el diseño paisajista de Roberto Burle Marx.

Mención especial merece la ciudad de Brasilia, concebida e inaugurada a fines de la década de 1950, cuyo plan piloto proyectado por Lucio Costa y los numerosos edificios diseñados por Oscar Niemeyer, consti- tuyen un caso único de urbanismo y arquitectura del movimiento moderno. Fue la primera obra del movimiento moderno del siglo XX en ser reconocida por la UNESCO.

La lista ha sido consultada en setiembre de 2019 en la página web World Heritage Centre - UNESCO. http:// whc.unesco.org/en

4 El organismo internacional encargado de la documentación y conservación de la arquitectura y el urbanismo del movimiento moderno es el DoCoMoMo, fundado en 1988. Se dedica a estudiar y evaluar obras construidas aproximadamente entre 1925 y 1965, incluso hasta 1975. Cuenta con representantes en varios países del mundo y, a nivel nacional, deberían ser los encargados de proteger edificios, sitios y barrios del movimiento moderno con valor arquitectónico y urbano, buscando su declaración como parte del patrimonio nacional, antes de llegar al reconocimiento mundial.

5 Son 13 edificios los que aparecen en la versión digital del Catálogo arquitectura movimiento moderno Perú en el rubro recreación y deporte. Se trata de 8 clubes, un centro vacacional (en Huampaní), un hipódromo (el de Monterrico), los baños de Miraflores, una concha acústica y el Estadio Nacional. De los trece, dos aparecen en su condición de proyectos, dos están demolidos y tres han sido radicalmente transformados. http:// cammp.ulima.edu.pe/\#3

6 Para la protección del patrimonio del siglo XX en el Perú era de gran importancia, primero, contar con una catalogación a fin de que el Ministerio de Cultura pudiera declarar de manera efectiva edificios notables, así como su divulgación a la comunidad para crear conciencia y memoria de la ciudad.

Hasta el 2018 la única obra del Movimiento Moderno que contaba con protección era la Casa Huiracocha que fue proyectada en 1947 por el arquitecto Luis Miro Quesada y debieron pasar 71 años para que el Ministerio de Cultura viera la importancia de preservar este legado arquitectónico y decidiera actuar.

En el año 2019 se elaboraron y entregaron cinco expedientes para la declaración de edificios emblemáticos, entre ellos el ex Ministerio de Educación actual edificio del Poder Judicial Javier Alzamora Valdez de Enrique Seoane Ros y el ex Banco Continental actual Ministerio de Relaciones Exteriores de Héctor Velarde.

Si bien el Ministerio de Cultura está haciendo una buena labor en adecuar sus políticas de declaración y en tratar de acelerar los procesos legales, la poca estabilidad debido a los continuos cambios en la dirección de los ministerios trunca los avances.

Así mismo, no existen actualmente leyes específicas para la protección del legado arquitectónico moderno y este no debería declararse con las mismas ordenanzas que el patrimonio colonial o del siglo XIX.

El patrimonio moderno debe poder intervenirse $y$ cambiar de uso para poder acoger las funciones actuales, considerarse como patrimonio vivo. De igual manera se tienen que seguir buscando incentivos para los dueños de edificios con valor patrimonial para alentarlos a que promuevan su declaración. Uno de los mecanismos lanzados por el Ministerio de Cultura es el programa "Altura para la cultura" que incentiva a que los propietarios de edificios con valor patrimonial inscriban sus inmuebles para su declaración y reci- 
ban a cambio un beneficio económico para restaurar el edificio a su estado original. La figura consiste en vender los aires edificables de acuerdo a los parámetros del lote a una empresa desarrolladora para que pueda construir más pisos en alguno de los distritos receptores de este programa. Si bien este mecanismo es pertinente para otros estilos, cuesta pensar que se aplique bien en el patrimonio moderno, pues se deben permitir intervenciones contemporáneas para el reciclaje de las edificaciones. Estas intervenciones deben revalorar el edificio entendiendo su importancia histórica, el lugar que ocupan en el imaginario colectivo de la ciudad, conservar la legibilidad del edificio, reforzar las estructuras más valiosas, recuperar los elementos característicos del edificio y liberar las zonas deterioradas o sin características esenciales modernas para su posterior intervención contemporánea y adecuación a un nuevo uso. Esto alineado con los postulados originales del Movimiento Moderno (adaptación y transformación).

\section{Referencias bibliográficas}

AAVV (2000) Guia da arquitetura moderna no Rio de Janeiro. Rio de Janeiro: Prefeitura da cidade do Rio de Janeiro, Centro de Arquitetura e Urbanismo do Rio de Janeiro

Acevedo, A; Llona, M. (2016) Catálogo arquitectura movimiento moderno Perú. Lima: Universidad de Lima.

Álvarez, G. (2007) Los estadios y el desarrollo del fútbol. Lima, 1892 - 1953. CAP Lima. Año 1, nº 4, julioagosto, $68-72$

-(2016). El fútbol en Lima, actores e instituciones. En A. Panfichi (Ed.) Ese gol existe. Una mirada al Perú a través del fútbol (pp. 29 - 62). Lima: Fondo Editorial de la Pontificia Universidad Católica del Perú.

(2019) El fútbol en Lima. Difusión y popularización (1892 - 1912). Lima: Municipalidad de Lima.

Anónimo (1952) El nuevo gran Estadio nacional. El Arquitecto Peruano, 185, 22-24, 30

Archivo BAQ Arquitectura Panamericana. (14 de diciembre de 2019). Archivo BAQ Arquitectura Panamericana: Rehabilitación y remodelación del Estadio Nacional. Obtenido de http://www.arquitecturapanamericana.com/rehabilitacion-y-remodelacion-del-estadio-nacional/

Carmona, L. (2012). Patrimonio arquitectónico de Montevideo: fases hacia el debate en la esfera pública (1980-2012). Instituto de Arte Americano e Investigaciones Estéticas "Mario J. Buschiazzo". Anales del IAA. 42 (2), 155-178. Obtenido de http://www.iaa.fadu.uba.ar/anales/anales42-2/ v42n2a07.htm

Comisión del Patrimonio Cultural de la Nación. (octubre de 2019). Patrimonio Uruguay. Recuperado el 6 de septiembre de 2019, de https://www.patrimoniouruguay.gub.uy/innovaportal/v/33442/68/ mecweb/monumentos-historicos-nacionales

Conti, A. (2015) Patrimonio latinoamericano del siglo XX en la Lista del Patrimonio Mundial. Recuperado de: https://www.academia.edu/24213254/Patrimonio_latinoamericano_del_siglo_XX_en_la_Lista_ del_Patrimonio_Mundial
Cuadra, M. (2010) Arquitectura en América Latina: Perú, Bolivia, Ecuador y Chile en los siglos XIX y XX. Lima: INIFAUA, Universidad Nacional de Ingeniería.

Fernandes Arquitetos Associados. Fernandes Arquitetos Associados. Recuperado el 16 de agosto de 2019, de http://fernandes.arq.br/projetos/maracana-copa-do-mundo-fifa-2014/

Junta de Andalucía Consejería de Vivienda y Ordenación del Territorio. (1992). Guía Arquitectónica y Urbanística. Montevideo: Junta de Andalucía Consejería de Vivienda y Ordenación del Territorio. Recuperado de https://montevideo.gub.uy/sites/ default/files/guia_arquitectonica_y_urbanistica_ cuarta_edicion.pdf

Leis Municipais do Rio de Janeiro. (25 de agosto de 2019). Sistema LeisMunicipais. Obtenido de https://leismunicipais.com.br/a1/ri/r/rio-de-janeiro/ decreto/2002/2167/21677/decreto-n-21677-2002-determina-o-tombamento-dos-bens-que-menciona-e-da-outras-providencias

Martuccelli, E. (2017) Arquitectura para una ciudad fragmentada. Ideas, proyectos y edificios en la Lima del siglo XX. Lima: Universidad Ricardo Palma.

Prefeitura do Rio de Janeiro / Patrimônio Cultural. (2014). Guia do patrimônio cultural carioca: bens tombados 2014. Rio de Janeiro: Instituto Rio Patrimônio da Humanidade. Recuperado el 23 de julio de 2019, de http://www.rio.rj.gov.br/dlstatic/10112/6442881/4172719/guiatombamentoport2o. 12baixa.pdf

Spósito, E. (2006) Centenario moderno. Apuntes. Vol. $19, n^{\circ} 2,274-283$, Pontificia Universidad Javeriana, julio diciembre.

Suárez Argüello, A. R., \& Sánchez Andrés, A. (2017). A la sombra de la diplomacia. Actores informales en las relaciones internacionales de México, siglos XIX y $X X$. Ciudad de México: Instituto de Investigaciones Históricas Universidad Michoacana de San Nicolás de Hidalgo. Recuperado el 18 de agosto de 2019, de https://www.academia.edu/36276554/ 